\title{
Sustentabilidade quanto às embalagens de alimentos no Brasil
}

\section{Sustainability concerning food packaging in Brazil}

\author{
Ana Paula Miguel Landim¹, Cristiany Oliveira Bernardo', Inayara Beatriz Araujo Martins', \\ Michele Rodrigues Francisco ${ }^{1}$, Monique Barreto Santos ${ }^{1}$ e Nathália Ramos de Melo ${ }^{1,2 *}$
${ }^{1}$ Departamento de Tecnologia de Alimentos - DTA, Universidade Federal Rural do Rio de Janeiro - UFRRJ, Seropédica, RJ, Brasil
${ }^{2}$ Departamento de Engenharia de Agronegócios, Escola de Engenharia Industrial Metalúrgica de Volta Redonda - EEIMVR, Universidade Federal Fluminense - UFF, Volta Redonda, RJ, Brasil
*nathaliarm@vm.uff.br

\begin{abstract}
Resumo
A mudança de hábito e o aumento do consumismo nas últimas décadas levaram a inovações tecnológicas e consequentemente à maior produção de bens de consumo, o que gerou um aumento na produção de embalagens. As embalagens estão presentes em diversos setores, dentre eles destacam-se as indústrias de alimentos, nas quais as embalagens têm como principal função contribuir para conservação do alimento, além de vender o produto. Diferentes materiais são utilizados na fabricação de embalagens para alimentos, sendo eles os plásticos, metais, vidro e celulose. Cada material possui suas diferentes características para conservar o produto, dentre elas as principais são propriedade de barreira a gases, aroma, luz, água, microrganismos e resistência mecânica. No entanto, apesar das diversas vantagens de sua utilização, seu uso e descarte desordenado gera um grande volume de resíduos sólidos, que estão associados ao impacto ambiental. Em preocupação a essa situação têm-se buscado meios alternativos para reduzir tais impactos podendo destacar a reutilização e reciclagem das embalagens, bem como o desenvolvimento de polímeros verdes e materiais biodegradáveis.
\end{abstract}

Palavras-chaves: meio ambiente, biodegradáveis, reciclagem, resíduos sólidos.

\begin{abstract}
Change of habits and increasing consumerism observed in the recent decades have widely influenced technological innovations, as well as the growth of consumer goods production, which has consequently required a crescent packaging production. Packages are used in diverse sectors, among them the food industry stand out, in which their main functions are to contribute to food conservation and selling the product. Different materials, such as plastics, metals, glass and paper, have been used in the food packaging production. Each material has different attributes that help to conserve the product: gas, aroma, light, water barrier, microorganisms and mechanical strength are the main ones. Despite the several advantages of its application, its uncontrolled use and disposal result in a large volume of solid residues and environmental impact. Concerning this situation, alternative practices, such as reuse and development of biodegradable and green polymers, have been considered in order to reduce the impacts.
\end{abstract}

Keywords: environment, biodegradable, recycling, solid residues.

\section{Introdução}

A vida contemporânea juntamente com as novas tecnologias têm causado um aumento na produção de resíduos sólidos. Grande parte destes permanece por centenas e milhares de anos no ambiente, causando não só uma crise ambiental ${ }^{[1]}$, como também um problema econômico e social. O grande consumo de produtos industrializados, como os alimentos, que necessitam de embalagens (primárias, secundárias e terciárias), resulta no aumento de resíduos sólidos e consequentemente em impacto ambiental.

Na sociedade moderna, a embalagem é um fator importante para medir a atividade econômica dos países industrializados, ou seja, o consumo de embalagens pela população é utilizado como um dos parâmetros para verificar o nível de atividade econômica e desenvolvimento dos países $^{[2]}$. Um bom desenvolvimento deve associar a utilização responsável dos recursos naturais disponíveis, com as expectativas econômicas, gerando benefícios para ambas as dimensões ${ }^{[3]}$, isto é, desenvolver de forma sustentável.

Historicamente, o conceito de desenvolvimento sustentável associa-se à preocupação na manutenção e na existência de recursos naturais para a continuidade das gerações futuras. Este não permite uma economia que desperdice recursos, que utilize energia não renovável, ou que destrua o valioso capital natural ${ }^{[4]}$. 
Para contribuir positivamente com a sustentabilidade, as embalagens devem ser fabricadas a partir de materiais oriundos de fontes ambientalmente corretas, com tecnologias limpas de produção, serem recuperáveis após a utilização, além de serem fabricadas, transportadas e recicladas utilizando energia renovável ${ }^{[5]}$. A sustentabilidade de um produto/embalagem também depende do consumidor, uma vez que se não for corretamente utilizado ou descartado, a sua sustentabilidade é inexistente.

\section{Embalagens}

Com a atual escassez mundial e o aumento no custo dos alimentos, a segurança alimentar e a segurança dos alimentos são questões frequentemente discutidas. Dessa forma, a política pública visa garantir que os diferentes setores de abastecimento de alimentos ofereçam produtos inócuos e seguros para um maior número de consumidores ${ }^{[6]}$. Sendo assim, embalagens de alimentos são um dos recursos utilizados, que funcionam como uma barreira inerte entre o alimento e o ambiente, proporcionando a segurança do produto e permitindo que estes tenham uma ampla distribuição.

A embalagem representou uma grande importância para o desenvolvimento do comércio e para o crescimento das cidades ao longo da história ${ }^{[7]}$. Em geral seu principal objetivo é proteger o produto, com a finalidade de preservar as características do alimento, por meio das propriedades de barreira aos fatores ambientais, tais como luz, umidade, oxigênio e microrganismos, mantendo o produto sem alterações indesejáveis durante o transporte e armazenamento ${ }^{[8]}$. Hoje as embalagens somam novas funções, como a de despertar o desejo de compra, transmitir informações, comunicação, ser suporte de ações promocionais e ainda mais recente tem-se a utilização de embalagens ativas, embalagens que interagem com o produto e das embalagens inteligentes que interagem com produto e comunicam com o consumidor. Desta forma, as embalagens passaram a conservar, expor, vender os produtos e por fim conquistar o consumidor por meio de seu visual atraente e comunicativo ${ }^{[7]}$.

As embalagens apresentam uma ampla variedade de formas e materiais e fazem parte do nosso cotidiano. Em tempos onde o consumo é alto, a competitividade é algo em que as empresas se deparam frequentemente, portanto criar e inovar são soluções fundamentais para se destacar nesse mercado. A inovação está envolvida, na maioria das vezes à resistência mecânica, associada com propriedades de barreira a gases e aromas, além de novos sistemas de fechamento, garantindo maior segurança e praticidade para o consumidor ${ }^{[9,10]}$. Porém, ainda é baixo o investimento para as inovações realmente sustentáveis. As poucas indústrias que optam por embalagens sustentáveis, geralmente voltam-se para o uso de materiais reciclados, muitas vezes por estratégia de marketing, não se preocupando com a produção de embalagens que utilizam matérias primas sustentáveis, e com baixo tempo de degradação.

Segundo a RDC 259/2002[11] embalagem é o recipiente, o pacote ou a embalagem destinada a garantir a conservação e facilitar o transporte e manuseio dos alimentos. Lautenschlager ${ }^{[12]}$ menciona que o conceito de embalagem varia conforme a perspectiva em que é observada. Para o consumidor, a embalagem é um meio de satisfazer o desejo de consumo do produto; para o marketing, a embalagem se torna o meio mais próximo do consumidor ser atraído para a compra do produto; para o setor de design, a embalagem é a forma de proteção até chegar ao consumidor; para a engenharia industrial é o meio de proteção do produto no transporte e armazenamento.

Segundo a Associação Brasileira de Embalagens $(\mathrm{ABRE})^{[13]}$, existem diversos tipos de embalagens que atendem a diversas funcionalidades, de acordo com o que se deseja para o produto final. Dentre elas, destacam-se as embalagens multicamadas, que podem ser cartonadas, laminadas, entre outras. As laminadas são formadas pela sobreposição de materiais, como filmes plásticos, metalizado e/ou papeis. Quando um destes é um papel cartão estas são denominadas cartonadas. Todas podendo ser ditas multicamadas. Esta mistura de materiais amplia a gama de produtos que podem ser embalados em uma mesma embalagem, porém, dificultam sua reciclagem.

De acordo com a utilização as embalagens são classificadas em primárias, secundárias e terciárias. As primárias estão em contato direto com o produto, já as secundárias têm a função de agrupar, para facilitar a manipulação e a apresentação, podendo exercer também a função de proteger a embalagem primária, em seu interior, evitando choques e vibrações excessivas. As embalagens terciárias protegem a mercadoria durante as fases do transporte e assim por diante $^{[14]}$. Vê-se que a necessidade, às vezes excessiva, em se tratar apenas de estética ou marketing, tem aumentado o volume de materiais utilizados em um único produto, o que torna crescente a quantidade de resíduo sólidos referente às embalagens.

Segundo a ABRE as indústrias de embalagens tiveram um crescimento de $1,41 \%$ em sua produção em 2013. As indústrias de embalagens registraram uma receita líquida de vendas de $\mathrm{R} \$ 51,8$ bilhões, o que equivale a um aumento de $11 \%$ em relação ao ano anterior. $\mathrm{O}$ valor bruto da produção de embalagens atingiu R \$ 52,4 bilhões, um aumento também de quase $11 \%$ em relação aos R\$ 47,3 bilhões de 2012 . Existem quatro tipos de materiais básicos para produção de embalagens de alimentos, os plásticos, metais, vidro e celulose-papel/papelão ${ }^{[13]}$.

\subsection{Plásticos}

Os plásticos são produzidos por meio da nafta obtida durante o refino do petróleo ${ }^{[15]}$. A partir desta matéria prima têm-se os monômeros, que por polimerização formam os polímeros - macromolécula. Esses polímeros quando formados por um único tipo de monômero são chamados homopolímeros e quando compostos de dois ou mais tipos de monômeros são chamados copolímeros.

Dividem-se em dois grandes grupos, termoplásticos e termofixos. Os termofixos são aqueles que sofrem reações químicas em sua moldagem as quais impedem uma nova fusão, portanto não são recicláveis. Os termoplásticos não sofrem alterações químicas quando aquecidos e depois de resfriadas podem novamente passar pelo processo de fundição ${ }^{[16-18]}$, podendo ser remoldados.

Os materiais plásticos vêm substituindo diversos tipos de materiais como o aço, vidro e madeira. De acordo com 
a ABRE, os plásticos representam $37,47 \%$ no valor total da produção de embalagens ${ }^{[13]}$. Eles têm como vantagens o seu baixo peso, baixo custo, elevada resistência mecânica e química, flexibilidade, possibilidade de aditivação e reciclabilidade ${ }^{[19,20]}$. A principal desvantagem é a sua variável permeabilidade à luz, gases, vapores e moléculas de baixo peso molecular. Outra desvantagem é serem, em sua maioria, não biodegradáveis e levarem mais de 100 anos para serem completamente degradados pela natureza ${ }^{[18-21]}$. Além disso, sua produção geralmente emite gases poluentes ao meio ambiente e é dependente do petróleo, um recurso natural do planeta não renovável.

Apesar disso, pela sua diversidade e versatilidade os polímeros proporcionam avanços tecnológicos, economia de energia e diversos outros benefícios para a sociedade por meio da produção de uma variedade de produtos ${ }^{[22]}$. De acordo com a Associação Brasileira da Indústria do Plástico (ABIPLAST) ${ }^{[23]}$ os polímeros mais consumidos atualmente são: Poli(etileno tereftalato) (PET); Polietileno de alta densidade (PEAD); Poli(cloreto de vinila) (PVC); Polietileno de baixa densidade (PEBD/PELBD); Polipropileno (PP); Poliestireno (PS); Acrilonitrilaextireno/resina (ABS/SAN); Espuma Vinílica Acetinada (EVA). Além das citadas, as Poliamidas (PA), os Policarbonatos (PC), os Poliuretanos, (PU, TPU, PUR), os Fluoropolímeros (PTFE) são produzidos em menor escala devido ao seu alto custo e aplicações específicas ${ }^{[23]}$.

O PET é um termoplástico que devido às suas características de alta resistência mecânica e química, excelente barreira a gases e odores, reciclabilidade, baixo peso, maleabilidade e elevada transparência tem sido amplamente utilizado pela indústria de bebidas. No entanto, o grande problema enfrentado por essas indústrias, diz respeito à migração de componentes do polímero para o alimento ${ }^{[24]}$. Esta embalagem reduz o desperdício nas indústrias, pois os custos com o transporte e a produção são menores, proporcionando um ótimo custo/benefício ${ }^{[24]}$. Segundo a Associação Brasileira de PET (ABIPET) a produção de PET's em 2011 foi de 515 mil toneladas com estimativa de 720 mil toneladas em 2014 e 840 mil toneladas em $2016^{[25]}$.

A grande produção e utilização de plásticos, leva ao volumoso descarte, que na maioria das vezes é desordenado, o que contribui para o impacto ao meio ambiente. É visível atualmente, principalmente nas grandes cidades, problemas com inundações decorrentes do descarte incorreto desses materiais, devido à ausência de consciência da própria população, das indústrias e dos sistemas ineficientes de coletas de lixo.

\subsection{Metal}

O metal oferece propriedades de proteção física e de barreira, formabilidade, reciclagem e é também muito aceito pelos consumidores devido sua versatilidade. As latas de metal fechadas hermeticamente suportam altas e baixas temperaturas de processamento, são impermeáveis à luz, umidade, odor e microrganismos o que confere proteção ao seu conteúdo ${ }^{[26]}$. De acordo com a ABRE as embalagens metálicas representam $16,03 \%$ no valor de produção no setor de embalagens ${ }^{[13]}$. Os metais mais utilizados para a formação de embalagens são o aço e o alumínio ${ }^{[18]}$.

\subsubsection{Aço}

As embalagens de aço possuem como matéria-prima o óxido de ferro, que quando aquecido dará origem ao aço que é utilizado como embalagem para alimentos, dentre outros tipos de utilidades. Para não oxidar, quando em contato com o ar, as latas de aço são tratadas com revestimentos de cromo ou estanho. As latas são fabricadas a partir de chapas metálicas, conhecidas como folhas de flandres ${ }^{[27]}$.

Esse tipo de embalagem permite a integridade do produto no transporte e comercialização, possui alta resistência mecânica, permite maior segurança aos produtos, pois possibilitam o processo de esterilização, além disso, é reciclável e degradável ${ }^{[28]}$. Entretanto, sofrem amassamento durante transporte e comercialização, e por ser um material não inerte, pode sofrer corrosão, além de permanecerem por mais de 100 anos no ambiente quando descartados ${ }^{[21]}$.

\subsubsection{Alumínio}

O alumínio não é encontrado em estado metálico na natureza, mas é o terceiro elemento mais abundante da crosta terrestre, sendo obtido a partir da bauxita submetida às etapas de refino e redução ${ }^{[26]}$. O Brasil está entre as maiores reservas de bauxitas do mundo, sendo o $6^{\circ}$ maior produtor mundial de alumínio e o $9^{\circ}$ maior consumidor mundial ${ }^{[29]}$.

Este metal é comumente usado para a fabricação de latas, papel alumínio, e papel ou plásticos laminados ou como filmes metalizados, de modo a melhorar as propriedades de barreira. O alumínio tem como grandes vantagens ser um material leve, impermeável a luz, umidade e odores, ser maleável, apresentar alta relação resistência/peso e resistência à corrosão ${ }^{[18]}$.

Podem ser utilizados para embalar produtos ácidos, como os refrigerantes, desde que seja utilizado verniz adequado. No entanto, não são utilizadas para embalar alimentos com alto teor salino, não tolera altas pressões nas autoclaves, possui um alto custo na produção em comparação com outros metais, não suportam agrafagem, sendo mais utilizado em recipientes sem costura. Sua degradação na natureza pode demorar de 100 a 500 anos, por isso a importância de ser reciclado ${ }^{[18-21]}$.

\subsection{Vidro}

Em geral os vidros são fabricados por um processo no qual as matérias primas (areia, barrilha, calcário e cacos de vidro) em proporções variadas são misturadas e fundidas a uma temperatura elevada entre $1350{ }^{\circ} \mathrm{C}$ a $1600{ }^{\circ} \mathrm{C}$, possibilitando, se necessário, a moldagem em diferentes formas e tamanhos. A alumina $\left(\mathrm{Al}_{2} \mathrm{O}_{3}\right)$ pode ser incorporada para melhorar a durabilidade química do vidro e agentes refinadores agem reduzindo a temperatura e o tempo que levaria no processo de fusão, auxiliando na remoção de bolhas de ar do vidro ${ }^{[26]}$ e economia de energia durante o processo de produção.

É um material inerte, garantindo a segurança do consumidor quanto à possibilidade de contaminação do alimento embalado. Possui características desejáveis como impermeabilidade a gases e vapor, praticidade, versatilidade, transparência, podendo apresentar variações de cor o que possibilita proteção aos produtos sensíveis à luz. No entanto, 
são pesados e frágeis, acarretando maior custo no transporte e consequentemente maior custo do produto final, além de ser necessária a utilização de outros tipos de materiais para o fechamento hermético das embalagens ${ }^{[21-27]}$.

$\mathrm{O}$ vidro é o material de embalagem mais antigo e corresponde a 4,86\% no valor de produção de embalagens no Brasil ${ }^{[30]}$. Apesar do seu tempo de degradação total no ambiente ser indeterminado, seu impacto no ambiente se torna menor por ser completamente reciclável e reutilizável.

\subsection{Celulose (papel/papelão)}

A partir da celulose são produzidas embalagens de papelão e papel, sendo amplamente utilizados em diversas indústrias, incluindo as de alimentos. Segundo a Associação Brasileira de Celulose e Papel (BRACELPA) ${ }^{[31]}$, o Brasil é um grande produtor mundial de papel, fazendo dele um exportador deste material. Em 2010 a sua colocação como produtor mundial de papel ficou em $10^{\circ}$ posição e em 2012 produziu 10,3 milhões de toneladas do produto. As embalagens celulósicas participam com $35,05 \%$ no valor bruto total de produção no setor de embalagens ${ }^{[13]}$. Caso essa produção não seja realizada de forma sustentável, como por exemplo, com a utilização de florestas plantadas, pode gerar um grave problema ambiental, uma vez que há alto gasto de energia, grande consumo de água e um volume elevado de florestas cortadas necessárias para a produção de papel.

O termo papelão abrange a cartolina, papelão aglomerado e placas de papelão corrugada ou sólidas. Estes são mais espessos, utilizados para proteção dos alimentos a danos mecânicos durante o transporte, raramente são usados em contato direto com alimentos ${ }^{[26]}$.

As vantagens da utilização do papel como embalagem de alimentos são variadas. Diversos tipos e formas podem ser produzidos, são recicláveis e por conta do tipo de matéria-prima são biodegradáveis, levando cerca de 6 meses para serem degradadas na natureza ${ }^{[21-26]}$

As embalagens formadas por celulose são altamente susceptíveis a danos ocasionados pela água e umidade, devido à sua natureza hidrofílica. Em virtude do que foi dito, são exigidas a impermeabilidade e outras características para contato direto com os alimentos, e isso é definido muitas vezes pelos processos utilizados nas indústrias, onde combinam papel com outros materiais, como os plásticos e metais. No entanto, essas embalagens se tornam mais caras e mais difíceis de serem recicladas ${ }^{[31]}$.

\section{Resíduos Sólidos}

Os resíduos sólidos são resíduos nos estados sólido e semi-sólido, que resultam de atividades da comunidade de origem: industrial, doméstica, hospitalar, comercial e agrícola $^{[32]}$.

O Brasil produziu aproximadamente 63 milhões de toneladas de resíduos sólidos urbanos (RSU) em 2012, uma média de $383 \mathrm{~kg}$ de lixo por ano/ habitante. Este volume é $1,3 \%$ superior ao registrado em 2011. No Brasil, cerca de $42 \%$ dos municípios tem destinado seus resíduos de maneira inadequada em lixões ou aterros controlados, isso equivale a quase 24 milhões de toneladas/ano ${ }^{[33]}$.

Esse descarte indevido gera grandes problemas como mau odor, a proliferação de vetores como ratos, baratas, Aedes aegypti (mosquito da dengue), assim como o desenvolvimento de microrganismos, alguns destes possíveis causadores de doenças e infecções. Além disso, em aterros não controlados, sem a seleção e cuidado com o resíduo sólido, possibilita a contaminação do solo e de águas subterrâneas, comprometendo os recursos hídricos, que são essenciais para vida.

A partir de dados do Compromisso Empresarial para Reciclagem (CEMPRE) ${ }^{[34]}$ estima-se que o Brasil gaste mais de 10 bilhões de reais em resíduos sólidos por ano, descontando o que é reciclado. Dentre esses resíduos sólidos 1/3 é composto por embalagens, o que o torna este setor um dos principais responsáveis pelo aumento do lixo no país.

Os resíduos sólidos são compostos geralmente de matéria orgânica biodegradável, material orgânico não biodegradável (plásticos) e de matéria inorgânica não degradável (vidro, metal e outros). Depois da matéria orgânica, o material de embalagem que tem maior participação no total de RSU coletado no Brasil são os plásticos com 13,5\% seguido do papel e papelão com $13,1 \%$, metais com $2,9 \%$ e vidro $2,4 \%{ }^{[33]}$.

Por mais que o uso de embalagens traga diversos benefícios como conservação, praticidade, armazenamento e transporte, seu uso desordenado gera um grande volume de resíduos sólidos que são associadas ao impacto ambiental ${ }^{[35]}$. Preocupados com essa situação, a partir da década de 1980 tem-se buscado meios de reduzir a quantidade de lixo produzido e o destino de embalagens após o uso ${ }^{[36]}$.

A Política Nacional de Resíduos Sólidos (PNRS), através da Lei $n^{\circ} 12.305 / 10$, incentivou a prevenção e redução da geração de resíduos por meios de mudanças de hábitos de consumo mais sustentáveis, além do incentivo às práticas de reciclagem, reutilização de resíduos sólidos e destino adequado dos rejeitos por meio de compostagem. Instituiu a responsabilidade compartilhada dos geradores de resíduos e impôs a elaboração de planos de gerenciamento de resíduos sólidos por particulares ${ }^{[37]}$.

\section{Avaliação do Ciclo de Vida}

Avaliação do Ciclo de Vida (AVC) é um método que tem por objetivo calcular os impactos ambientais causados por um determinado produto, um processo ou uma atividade, o que permite sugerir alternativas que causem menor impacto possível no meio ambiente ${ }^{[38]}$. As embalagens afetam o meio ambiente devido ao tempo que requerem para serem completamente degradadas, quando eliminadas e também pelos processos utilizados para sua reciclagem ${ }^{[39]}$.

Apesar do impacto ambiental gerado pelas embalagens, estas reduzem o desperdício de alimentos, tendo um papel importante para segurança alimentar e na redução do impacto ambiental gerado pelo próprio alimento ${ }^{[40]}$. No entanto, a função da embalagem no que diz respeito à redução do desperdício não é levado em conta nos estudos da AVC, sendo contraditório, uma vez que o alimento muitas vezes tem um impacto ambiental maior que o causado pelas embalagens $^{[41]}$. Assim, para reduzir o impacto ambiental causado pelo ciclo de vida da embalagem de alimentos é crucial que a mesma seja capaz de reduzir o desperdício de alimentos, além de ser sustentável. 


\section{Sustentabilidade}

A Comissão Mundial sobre Meio Ambiente e Desenvolvimento (CMMAD) ${ }^{[42]}$, publicou um relatório inovador, "Nosso Futuro Comum", que traz o conceito de desenvolvimento sustentável. Esta considera o desenvolvimento sustentável aquele que não degrada a natureza para satisfazer às necessidades da geração presente, ou seja, não compromete as necessidades das gerações futuras. Schmidheiny ${ }^{[43]}$, adverte que não é possível um desenvolvimento econômico sem prejuízo da natureza, mas saber administrá-la é fator principal.

As empresas utilizam cada vez mais estratégias para conquistar o consumidor, devido ao crescente consumo na sociedade capitalista. As indústrias de embalagens estão adequando sua produção à medida que a preocupação com o meio ambiente aumenta, buscando processos e produtos sustentáveis. As embalagens sustentáveis surgem como uma ferramenta estratégica de marketing para divulgação da marca e produto, se tornando um dos fatores que podem contribuir para decisão da compra ${ }^{[44]}$. Dentre as estratégias mais utilizadas pela indústria de embalagens encontram-se a utilização de embalagens recicláveis, polímeros verdes e os biodegradáveis.

\section{Reciclagem}

Um dos pontos mais importantes no gerenciamento sustentável é a reciclagem de embalagens, sendo esta também uma oportunidade de geração de emprego e renda para a população, além de sintetizar vários princípios do que é desenvolver de forma sustentável ${ }^{[45]}$. É definida como o processo de transformação dos resíduos sólidos que envolvem a alteração de suas propriedades físicas, físico-químicas ou biológicas, com vistas à transformação em insumos ou novos produtos, observadas as condições e os padrões estabelecidos pelos órgãos competentes ${ }^{[37]}$. Os quatro materiais mais usados para produção de embalagens de alimentos possuem consideráveis participações nas atividades de reciclagem no país.

\subsection{Reciclagem das embalagens plásticas}

Segundo Plastivida ${ }^{[46]}$, a reciclagem plástica no Brasil em 2010 foi de 953 mil toneladas, apresentando um crescimento de $2,5 \%$ em relação a 2009. Apesar desse crescimento, o plástico como um todo, ainda é o material com menor taxa de reciclagem, sendo potenciais alvos para políticas específicas de estímulo à reciclagem. Seu baixo índice de reciclagem pode ser explicado pelo baixo custo de produção, não sendo interessante para a indústria o gasto com a reciclagem, bem como a utilização desses materiais reciclados, uma vez que a qualidade é reduzida a cada ciclo de reciclagem e principalmente pela sua complexidade.

O PET é o polímero que vem obtendo melhor resultado, com taxas de reciclagem pós-consumo próximo a $60 \%$. O PEBD aparece em segundo lugar, com uma reciclagem pós-consumo de cerca de $20 \%$; todos os outros polímeros, porém, apresentam taxas inferiores a $10 \%{ }^{[47]}$.

A reciclagem de embalagens PET é crescente, em 1998 apresentou 13 mil toneladas havendo um aumento para 331 mil toneladas em 2012, correspondendo a um índice de
$58,9 \%$ de embalagens PET recicladas no Brasil. Seu mercado evolui de forma significativa, de forma que grande parte dos veículos nacionais produzidos atualmente sai de fábrica com seu interior revestido de materiais feito com PET reciclado, além disso, são utilizados para produção de roupas e tecidos. As aplicações do PET reciclado com melhores perspectivas de crescimento são bottle-to-bottle (46\%), têxtil (25\%), automotivo $(11 \%)$ e outras áreas $(18 \%)^{[47,48]}$.

A reciclagem de embalagens plásticas é bastante complexa, devido à diversidade de polímeros existentes, cada um com usos específicos e importância diferenciada nos resíduos sólidos. Esta complexidade se torna um dos principais desafios para a recuperação do plástico e a reciclagem de resíduos plásticos misturados somente é usada para a fabricação de produtos de menor valor ${ }^{[47]}$.

A recuperação ou reciclagem dos resíduos sólidos plásticos pode ser realizada por diferentes técnicas como re-extrusão, mecânica, química e recuperação energética. A reciclagem feita pelo processo de re-extrusão (reciclagem primária) faz-se pela reintrodução de sucatas e fragmentos de polímeros no ciclo para a fabricação de produtos de materiais similares, neste processo são utilizados plásticos com características semelhantes aos produtos originais ${ }^{[49]}$.

A reciclagem mecânica (reciclagem secundária) consiste na conversão dos descartes plásticos em grânulos usados na elaboração de outros produtos plásticos com exceção de embalagens alimentícias. É o método mais utilizado, porém só pode ser realizado em produtos com apenas um tipo de resina plástica ${ }^{[50]}$. A maioria dos plásticos pode ser submetida à reciclagem mecânica, mas os que de fato são reciclados variam dependendo da área de utilização. A seleção dos materiais está relacionada com seu valor econômico e volume de material disponível para reciclagem ${ }^{[51]}$.

Já a reciclagem química (reciclagem terciária) consiste em um reprocesso dos plásticos, transformando-os em petroquímicos básicos que servem como matéria-prima, em refinarias ou centrais petroquímicas, para a obtenção de produtos nobres de elevada qualidade ${ }^{[52]}$.

Na reciclagem por recuperação energética (reciclagem quaternária) faz-se a queima dos resíduos gerando calor, vapor ou energia. Neste processo há destruição de espumas, grânulos, cloroflurocarboneto (CFCs) e outros agentes nocivos $^{[50]}$. Embora a reciclagem energética ainda não exista no Brasil, é uma alternativa ambientalmente correta, economicamente viável e socialmente recomendável, o que a torna uma técnica sustentável ${ }^{[52]}$.

\subsection{Reciclagens das embalagens metálicas}

As embalagens metálicas correspondem a cerca de $26 \%$ do mercado de embalagens no Brasi ${ }^{[13]}$, sendo as principais embalagens produzidas, alumínio e aço. Dentre os metais, o mais reciclado é o alumínio, que detém uma posição de destaque, por ser reciclado infinitas vezes sem perder suas características no processo de reaproveitamento e apresenta um índice de reciclagem acima de $90 \%{ }^{[45]}$. O alto valor do mercado de sucata de alumínio, como latas prensadas, chaparias e latas soltas, que apresentam um valor médio de 3,$52 ; 3,84 ; 3,33 \mathrm{R} \$ / \mathrm{kg}$, respectivamente, e o elevado gasto de energia necessário para a produção de alumínio metálico oriundo de bauxita, são importantes fatores que fazem com 
que este metal possua um alto índice de reciclagem ${ }^{[53]}$. Uma lata de alumínio em aproximadamente 30 dias, pode ser comprada no supermercado, utilizada, coletada, reciclada e voltar às prateleiras para o consumo.

Atualmente, a reciclagem de alumínio no Brasil funciona com altíssimos índices de eficácia, acima da média mundial, reciclando praticamente todas as embalagens disponíveis. Em 2011, o Brasil reciclou 473 mil toneladas de alumínio, correspondente a $36,4 \%$ do consumo doméstico registrado, o que garante uma posição de destaque em eficiência no ciclo de reciclagem, cuja média mundial é de $28,3 \%{ }^{[33]}$. Já em 2012, o país reciclou 508 mil toneladas, desse total, 267,1 mil toneladas referem-se à sucata de latas de alumínio para bebidas $^{[53]}$.

A reciclagem do alumínio proporciona além da geração de renda para milhares de pessoas, a economia de milhões de toneladas de bauxita, havendo uma economia anual de energia que equivale ao abastecimento de uma cidade com mais de um milhão de habitantes, contribuindo dessa forma para um meio ambiente mais limpo e sustentável ${ }^{[54]}$. Assim como as embalagens de alumínio, as embalagens produzidas com aço também são $100 \%$ recicláveis, são reutilizáveis, trabalham constantemente a redução nos níveis de $\mathrm{CO}_{2}$ no processo de fabricação e a maximização do índice de reciclagem, limita o uso de combustíveis fósseis e tem avançado tecnologicamente na redução do peso da lata para que sejam gerados menos resíduos pós-consumo ${ }^{[28]}$.

Na indústria de alimentos são utilizadas em embalagens de leite em pó $(62 \%)$, leite condensado $(77 \%)$, creme de leite $(33 \%)$, óleos $(13 \%)$, azeites $(70 \%)$ e extratos de tomate (60\%). Em 2008, segundo o Instituto de Pesquisa Econômica Aplicada (IPEA) ${ }^{[47]}$ foram recicladas 97 mil toneladas de embalagens de aço no Brasil. Em 2012 foram reciclados cerca de 427,5 milhões de toneladas de aço, no mundo ${ }^{[34]}$.

Segundo a Associação Brasileira de Embalagens de Aço (ABEAÇO) ${ }^{[28]}$, cerca de $47 \%$ do total de latas de aço produzidas no Brasil são recicladas, representando aproximadamente 280 mil toneladas de material reciclado anualmente. O maior índice de retorno de latas de aço coletadas é no segmento de bebidas, com $82 \%$ das latas de aço para bebidas, retornando ao processo.

\subsection{Reciclagem das embalagens de vidro}

As embalagens, principalmente de alimentos, têm um papel importante para as fábricas de vidro, uma vez que são responsáveis por cerca de $40 \%$ do consumo deste material[ ${ }^{[47]}$. No ano de 2008 a produção de embalagens no setor vidreiro foi de 1,292 milhões de toneladas, segundo Associação Brasileira de Empresas de Limpeza Pública e Resíduos Especiais (ABRELPE) ${ }^{[33]}$.

A participação do vidro nos resíduos sólidos urbanos apresenta algumas dificuldades técnicas, como a reciclagem de vidros diferentes, por exemplo, vidros de embalagem junto com vidros planos ${ }^{[47]}$, estes devem ser separados dificultando o processo. Mesmo assim, cerca de $47 \%$ das embalagens de vidro foram recicladas em 2010 no Brasil, somando 470 mil toneladas/ano. Desse total, $40 \%$ são oriundos da indústria de envaze, $40 \%$ do mercado difuso, $10 \%$ do "canal frio" (bares, restaurantes, hotéis, etc.) e 10\% do refugo da indústria ${ }^{[34]}$.
Além da reciclagem há a possibilidade da reutilização das embalagens de vidro pela própria indústria, como no caso do setor de bebidas, ou pelo mercado informal, sendo estimado que cerca de $20 \%$ das embalagens sejam reutilizadas pela indústria e $33 \%$ pelo reuso caseiro e informal ${ }^{[33-47]}$.

\subsection{Reciclagem de embalagens de celulose (papel/ papelão)}

Em 2010 o Brasil reciclou 45,5\% de pape ${ }^{[31]}$ e a taxa de recuperação de ondulados e kraft foi de $71,1 \%$, a maior entre todos os tipos de papel ${ }^{[55]}$. Como a qualidade das fibras é prejudicada no processo de reciclagem, esses materiais são geralmente utilizados para fabricação de papelão, papéis de fins sanitários ou papel pardo e jornal, que não demandam a mesma qualidade de textura para imprimir e escrever.

A produção de papel é importante para economia mundial, pois representa cerca de $2,5 \%$ da produção industrial e $2 \%$ do comércio mundial. Os produtos de papel são utilizados não só na educação e comunicação como também na área da saúde e produção de embalagens. No entanto, tem gerado preocupações em relação ao uso não sustentável dos recursos florestais, a poluição industrial, o consumo exagerado e contribuição para a montagem de volumes de resíduos ${ }^{[56]}$.

De acordo com a BRACELPA ${ }^{[31]}$, o Brasil é um grande produtor de papel e $100 \%$ desse produto é proveniente de florestas plantadas. Em 2010 , o setor foi o $10^{\circ}$ maior produtor mundial, e em 2013 produziu 10,44 milhões de toneladas. Essa crescente produção de papel aumenta a demanda por fontes de energia, levando a maiores emissões de gases que causam o efeito estufa ${ }^{[57,58]}$. Para reduzir esse impacto, especialmente na produção de papel para jornal, a medida mais eficiente tem sido a substituição de celulose termo-mecânica (TMP) pela pasta reciclada, a qual o processamento consome menos energia elétrica ${ }^{[58,59]}$.

A produção de papel a partir de fibras recicladas, além de consumir menos energia, economiza recursos naturais e diminui a poluição ambiental ${ }^{[60]}$. Para cada tonelada de papel reciclado, vinte e duas árvores deixam de ser cortadas ${ }^{[61]}$. Uma das vantagens do papel é exatamente sua capacidade de reciclabilidade ${ }^{[62]}$, a produção e utilização de papel reciclado estão bem estabelecidas e amplamente aceitas ${ }^{[60]}$.

Em países desenvolvidos, a reciclagem de resíduos de papel é organizada e operada pelas autoridades municipais e apoiados pela política nacional, normalmente com base no princípio do "poluidor paga"[60]. Na Europa, papel e cartão, em parte ou totalmente produzido a partir de fibras recicladas, já estão sendo utilizados em contato com certos alimentos. No entanto, estudos que analisaram várias amostras de alimentos comerciais quanto à presença de bisfenol $\mathrm{A}$ (BPA), bis (2-etil-hexil) ftalato (DEHP), monoetoxilato de nonilfenol (NMP) e de di-nonilfenolethoxilate (NDP), que são substâncias presentes em papel reciclado, verificaram que nem todas as amostras continham todos os contaminantes, porém os contaminantes que foram encontrados estavam em altas concentrações, o que pode ser um limitante para que materiais de celulose reciclados sejam utilizados em contato direto com produtos alimentícios ${ }^{[63]}$.

Embora evite a derrubada de florestas, a reciclagem do papel pode causar outros impactos, uma vez que utiliza substâncias tóxicas, que se não forem tratadas corretamente 
são altamente poluentes. Sendo assim, deve-se verificar se esta prática está sendo realizada para ajudar a reduzir impactos ambientais ou se é apenas uma ferramenta para atrair consumidores, como estratégia de marketing.

\subsection{Reciclagem de embalagem multicamada (Cartonada Longa-vida)}

As embalagens multicamadas são aquelas elaboradas a partir de combinações de dois ou mais materiais, como o papel, PE e alumínio $(\mathrm{Al})^{[64]}$, com a função de promover melhor propriedade de barreira, além de maior praticidade. Dentre os tipos de embalagens multicamadas, as cartonadas são as mais utilizadas principalmente para processos UAT (Ultra Alta Temperatura).

As embalagens cartonadas, utilizadas em processo UAT, também chamadas Longa-vida, estão presentes no Brasil desde $1957^{[65]}$. São embalagens que apresentam um caráter de compósito laminado, uma vez que são produzidas pela combinação de papel cartão, polímero de baixa densidade (PEBD) e Al[66]. Essa embalagem era comumente utilizada para envasar leite, porém, no decorrer dos anos, os cartonados Longa-vida passaram a embalar outros alimentos, como suco, creme de leite, leite condensado, extrato de tomate, entre outros ${ }^{[67]}$.

Apesar de possibilitar menor gasto de energia, uma vez que não há necessidade de refrigeração do alimento e menor gasto de combustíveis devido à facilidade do transporte, manuseio e armazenamento dessas embalagens, são de difícil reciclagem e degradação no ambiente devido a grande agregação dos diferentes materiais com características químicas e físicas bem distintas. Além disso, a degradação das embalagens cartonadas é incerta, no entanto leva-se em consideração a degradação do alumínio que é superior a $100 \operatorname{anos}^{[67]}$.

A fim de solucionar esse problema, nos últimos anos houve um avanço nas técnicas de reciclagem e um crescimento de empresas que reciclam tais embalagens. Segundo Agamuthu e Visvanathan ${ }^{[68]}$, a reciclagem pode ser realizada por meio da técnica de hidro-polpação, sendo um processo que não necessita a utilização de aditivos químicos. Consiste em misturar a embalagem em água sob constante agitação. Nesse processo, são separadas as fibras de celulose do $\mathrm{PE} / \mathrm{Al}$ que é suspenso em água e logo é separado por bombeamento, centrifugado, seco e embalado para ser transportado para a fábrica de reciclagem. $\mathrm{O} \mathrm{PE} / \mathrm{Al}$ recuperado, pode ser utilizado em vários produtos inovadores, como material de cobertura, peças plásticas, etc. Enquanto que as fibras de celulose são lavadas, purificadas e destinadas à produção de papel reciclado utilizado na confecção de caixas de papelão, entre outros.

Os autores também relatam que a reciclagem de tais embalagens pode ser realizada pela tecnologia de plasma, desenvolvida no Brasil, que permite a separação do PE e do Al. Essa tecnologia consiste em usar a energia elétrica para produzir um jato de plasma a $15 \mathrm{mil}{ }^{\circ} \mathrm{C}$ para aquecer a mistura de plástico e alumínio ${ }^{[68]}$. Os produtos originados são o alumínio em pó ou em barra, usados na composição de tintas metálicas ou peças para a indústria de fundição, e a parafina, utilizada na produção de impermeabilizantes, lubrificantes ou como matéria-prima para a indústria química ${ }^{[69]}$.
Em 2011 o percentual de reciclagem no mundo foi de 21,6\%, enquanto que no Brasil em 2012 houve uma reciclagem de $29 \%$ das embalagens Longa-vida pós-consumo, totalizando 61 mil toneladas ${ }^{[70]}$, mostrando o quanto o Brasil se destaca na reciclagem deste segmento. Existem 35 recicladoras de caixas Longa-vida no país, com faturamento de R $\$ 80$ milhões por ano ${ }^{[34]}$.

As embalagens Longa-vida, passaram a ser utilizadas para o reaproveitamento na produção de papel ondulado, papel kraft, embalagens para ovos, produção de móveis e divisórias, vassouras, telhas, produção de energia (através de sua incineração $)^{[34]}$, reutilização na forma de painéis térmicos, substituindo produtos similares encontrados no mercado $^{[66]}$, além da possibilidade de produção de pellets (granulados) de PE e Al para peças diversas, como canetas, capas de caderno, pastas, pisos desmontáveis, lixeiras, entre outros itens.

\section{Polímeros Verdes}

Os produtos verdes são aqueles ambientalmente corretos, que não agridem o meio ambiente e a saúde humana ${ }^{[61-71]}$ e além de atenderem às normas legais, possuem outros atributos ambientalmente responsáveis ${ }^{[72]}$. Esses materiais são assim classificados não só baseado no produto final, como também na observação e análise de toda sua cadeia produtiva $^{[61]}$. Alguns materiais de embalagens podem ser citados dentro desse grupo, como exemplo, os polímeros verdes. Como denominação, a esses polímeros é acrescentado à palavra "verde" após a citação de sua nomenclatura: PVC Verde, PP Verde, PE Verde.

Os polímeros verdes podem ser classificados como sustentáveis, pois durante sua síntese, processamento ou degradação produzem menor impacto ambiental que os polímeros convencionais. São assim denominados, porque durante sua produção há absorção de $\mathrm{CO}_{2}$, além de menor dependência de matérias-primas de origem fóssil ${ }^{[73]}$, a qual podem ser substituídas por fontes renováveis como, por exemplo, milho, cana-de-açúcar ou celulose. Após o final da vida útil, os polímeros verdes podem ser reutilizados, reciclados ou enviados para sistemas de reciclagem energética, na qual há emissão neutra de carbono, onde o $\mathrm{CO}_{2}$ liberado na atmosfera é novamente capturado pela próxima safra ${ }^{[73]}$. A reciclagem de uma tonelada de garrafas de polímero verde pode poupar a emissão de até 1,5 toneladas de $\mathrm{CO}_{2}{ }^{[74]}$.

Um polímero verde apresenta as mesmas características finais de um polímero proveniente de fonte fóssil, tendo seu descarte, a mesma problemática. Vale ressaltar que muitos ligam a palavra "verde" como se fosse "biodegradável" e não procede. Um polímero "verde" é dito sustentável e não necessariamente biodegradável.

A Braskem inaugurou em 2010, no Brasil, a produção do PE verde em escala industrial e comercial. Produzido a partir do etanol de cana-de-açúcar, o PE verde, colabora para a redução da emissão dos gases causadores do efeito estufa, pois durante sua produção há captura e fixação de gás carbônico da atmosfera. O PEAD verde possui as mesmas funções, características e aplicações que PE provenientes de recursos fósseis. Porém comparado aos $\mathrm{PE}$ à base de petróleo ou gás natural, PEAD verde usa 70\% menos combustível fóssil e 
emitem, aproximadamente, $170 \%$ menos gases causadores do efeito estufa ${ }^{[74]}$. O PEAD verde é uma alternativa viável na substituição de PEAD convencional para embalagens de produtos de grande consumo, como os alimentos.

Assim como o PE, o PVC verde, também é produzido a partir do etanol de cana-de-açúcar. No Brasil a empresa responsável por sua produção é a Solvay Indupa, multinacional belga $^{[73]}$.

\section{Embalagens Biodegradáveis}

A não reutilização e reciclagem das embalagens pode gerar um problema ambiental, devido ao uso indiscriminado e descarte irresponsável destes resíduos. Dentre as embalagens mais utilizadas, os plásticos convencionais são os mais descartados de forma indevida no meio ambiente, podendo causar poluição de rios, mares e solos ${ }^{[75]}$. Esses plásticos convencionais, que são sinteticamente derivados do petróleo, não são facilmente degradados.

A biodegradação é um processo natural e complexo onde compostos orgânicos, por meio de mecanismos bioquímicos, são convertidos em compostos simples e, então, redistribuídos no meio ambiente, através do ciclo elementar do carbono, nitrogênio e enxofre ${ }^{[76]}$, ou seja, a biodegradação de um polímero é o processo pelo qual microrganismos e suas enzimas consomem este polímero como fonte de nutrientes, em condições normais de umidade, temperatura e pressão.

Os materiais plásticos convencionais, produzidos a partir de polímeros sintéticos ocasionam graves problemas ambientais, devido ao longo tempo necessário para a sua degradação, tem alta massa molar e são hidrofóbicos, o que dificulta a ação dos microrganismos e de suas enzimas na superfície do polímero ${ }^{[77,78]}$. O aumento da preocupação mundial com o meio ambiente tem impulsionado a produção de embalagens biodegradáveis como uma opção viável para a gestão destes resíduos ${ }^{[79]}$.

Os polímeros melhor adaptados à biodegradação completa são os naturais, aqueles hidrolisáveis a $\mathrm{CO}_{2}$ e $\mathrm{H}_{2} \mathrm{O}$, ou a $\mathrm{CH}_{4}$ e os polímeros sintéticos que possuem estruturas próximas aos naturais ${ }^{[80,81]}$.

Os polímeros biodegradáveis podem ser obtidos a partir de fontes naturais renováveis como milho, celulose, batata, cana-de-açúcar, ou serem sintetizados por bactérias a partir de pequenas moléculas como o ácido butírico ou o ácido valérico, dando origem ao polihidroxibutirato e ao polihidroxibutirato-co-valerato, respectivamente, ou até mesmo serem derivados de fonte animal, como a quitina, a quitosana ou proteínas ${ }^{[2,83]}$.

Outros polímeros biodegradáveis podem ser produzidos a partir de fontes fósseis, petróleo, ou da mistura entre biomassa e petróleo. Os polímeros biodegradáveis provenientes do petróleo mais conhecidos são as policaprolactonas (PCL), as poliesteramidas, os copoliésteres alifáticos e os copoliésteres $\operatorname{aromáticos}^{[73]}$.

Os polímeros biodegradáveis mostram um campo em desenvolvimento, com crescente utilização de polímeros não só para embalagens, bem como para os mais variados setores, se tornando uma área de grande potencial de estudos para viabilização do seu uso ${ }^{[84]}$. No entanto, algumas dificuldades devem ser superadas, que são o nível de consciência de utilização destes polímeros, que no Brasil é ainda muito baixo, e representa um desafio considerável, além do seu custo e desempenho, quando comparado aos das resinas convencionais $^{[73]}$.

\section{Considerações Finais}

O uso de embalagens tem se tornado indispensável para a sociedade, pois desempenha diversas funções importantes tanto para garantir a qualidade do produto, quanto para vendê-lo. Neste contexto, surge a preocupação com o destino final das embalagens e com os impactos que podem causar no meio ambiente, uma vez que possuem os mais diversos tipos de materiais com diferentes tempos de degradação. A busca pelo desenvolvimento de embalagens sustentáveis tem aumentado. Embalagens recicláveis, biodegradáveis e polímeros verdes, têm sido produzidos para reduzir o impacto ambiental. As indústrias, principalmente de alimentos, devem buscar desenvolver embalagens que utilizam a menor quantidade possível de material para um mesmo produto. Além disso, a população deve ser incentivada, por meio de políticas públicas, a reduzir o consumo e o descarte inadequado de tais embalagens.

O impacto ambiental causado pelas embalagens é um assunto que já vem sendo discutido há alguns anos, no entanto novas alternativas devem ser buscadas a fim de reduzir ainda mais os danos causados por este setor.

\section{Agradecimentos}

UFRRJ, CAPES, FAPERJ, CNPq, UFF.

\section{Referências}

1. Rahmani, E., Dehestani, M., Beygi, M. H. A., Allahyari, H., \& Nikbin, I. M. (2013). On the mechanical properties of concrete containing waste PET particles. Construction \& Building Materials, 47, 1302-1308. http://dx.doi.org/10.1016/j. conbuildmat.2013.06.041.

2. Mestriner, F. (2004). Design de embalagem: curso básico. São Paulo: Makron Books.

3. Silva, C. L., \& Mendes, J. T. G. (2005). Reflexões sobre o desenvolvimento sustentável: agentes e interações sob a ótica multidisciplinar. Petrópolis: Vozes.

4. Fresner, J. (1998). Cleaner production as a means for effective environmental management. Journal of Cleaner Production, 6(34), 171-179. http://dx.doi.org/10.1016/S0959-6526(98)00002-X.

5. The Consumer Goods Forum. (2011). A global language for packaging and sustainability. São Paulo: ABRE. Recuperado em 28 de agosto de 2014, de http://www.abre.org.br/eng/ wpcontent/uploads/2012/08/small_-global_protocol.pdf

6. Sonneveld, K. (2000). What drives (food) packaging innovation. Packaging Technology and Science, 13(1), 29-35. http://dx.doi. org/10.1002/(SICI)1099-1522(200001/02)13:1<29::AIDPTS489>3.0.CO;2-R.

7. Mestriner, F. (2002). Design de embalagem curso básico. São Paulo: Makron Books.

8. Sarantópoulos, C. I. G. L., Oliveira, L. M., Coltro, L., Vercelino, A. R. M., \& Corrêa, G. E. E. (2002). Embalagens plásticas flexiveis: principais polimeros e avaliação de propriedades. Campinas: CETEA/ ITAL. 
9. Castro, A. G., \& Pouzada, A. S. (1991). As embalagens para a indústria alimentar. Portugal: Instituto Piaget.

10. Schimmelfenig, C., Santos, D. M., \& Bernieri, E. (2009). Inovação de embalagens. Revista de Administração e Ciências Contábeis do IDEAU, 4(9), 1-15.

11. Brasil. Resolução RDC $n^{\circ}$ 259, de 20 de setembro de 2002. Aprova o regulamento técnico sobre rotulagem de alimentos embalados. Diário Oficial da União, Brasília.

12. Lautenschlager, B. I. (2001). Avaliação de embalagem de consumo com base nos requisitos ergonômicos informacionais (Dissertação de mestrado). Universidade Federal de Santa Catarina, Florianópolis.

13. Associação Brasileira de Embalagens -ABRE. (2014). Estudo macroeconômico da embalagem. São Paulo. Recuperado em 28 de agosto de 2014, de http://www.abre.org.br/setor/dadosde-mercado/

14. Cortez, A. T. C. (2011). Embalagens: o que fazer com elas. Revista Geográfica de América Central, 2(47E), 1-15. Recuperado em 28 de agosto de 2014, de http://www.revistas.una.ac.cr/ index.php/geografica/article/view/2568/2453

15. Machado, E. L. (2002). Economia de baixo carbono: petróleo e petroquímica. São Paulo: EBC.

16. Paine, F. A., \& Paine, H. Y. (1992). A handbook of food packaging. Glasgow: Blackie Academic and Professional.

17. Hernandez, R. J., Selke, S. E. M., \& Culter, J. D. (2000). Plastics packaging: properties, processing, applications and regulations. Munich: Hanser.

18. Marsh, K., \& Bugusu, B. (2007). Food packaging: roles, materials, and environmental issues. Journal of Food Science, 72(3), 39-55. http://dx.doi.org/10.1111/j.1750-3841.2007.00301.x. PMid:17995809.

19. Henningsson, S., Hyde, K., Smith, A., \& Campbell, M. J. (2004). The value of resource efficiency in the food industry: a waste minimisation project in East Anglia UK. Journal of Cleaner Production, 12(5), 505-512. http://dx.doi.org/10.1016/ S0959-6526(03)00104-5.

20. Schwark, F. (2009). Influence factors for scenario analysis for new environmental technologies: the case for biopolymer. Technology Journal of Cleaner Production, 17(7), 644-652. http://dx.doi.org/10.1016/j.jclepro.2008.11.017.

21. Santos, A. M. P \& Yoshida, M. P. (2011). Embalagem (Técnico em Alimentos). Recife: UFRPE. Recuperado em 28 de agosto de 2014, de http://200.17.98.44/pronatec/wp content/ uploads/2013/06/Embalagem.pdf

22. Andrady, A. L., \& Neal, M. A. (2009). Applications and societal benefits of plastics. Philosophical Transactions of the Royal Society of London. Series B, Biological Sciences, 364(1526), 1977-1984. http://dx.doi.org/10.1098/rstb.2008.0304. PMid: 19528050 .

23. Associação Brasileira da Indústria do Plástico - ABIPLAST. (2013). Perfil 2013. São Paulo. Recuperado em 7 de fevereiro de 2014, de http://www.abiplast.org.br/site/estatisticas

24. Bach, C., Dauchy, X., Severin, I., Munoz, J. F., Etienne, S., \& Chagnon, M. C. (2013). Effect of temperature on the release of intentionally and non-intentionally added substances from polyethylene terephthalate (PET) bottles into water: Chemical analysis and potential toxicity. Food Chemistry, 139(1-4), 672-680. http://dx.doi.org/10.1016/j.foodchem.2013.01.046. PMid:23561160.

25. Associação Brasileira da Indústria do Pet - ABIPET. (2013). Nono censo da reciclagem de pet. Brasil: o ano de 2012. São Paulo. Recuperado em 28 de agosto de 2014, de http://abipet. org.br/indexAjax.html?method=baixarArquivo\&id=437

26. Fellows, P. J. (2006). Tecnologia do processamento de alimentos: princípio e prática. São Paulo: Artmed.
27. Gava, A. J. (2009). Tecnologia de alimentos: princípio e aplicações. Rio de Janeiro: Nobel.

28. Associação Brasileira de Embalagens de Aço - ABEAÇO. (2010). Nosso aço uma história para ser contada. São Paulo. Recuperado em 28 de agosto de 2014, de http://www.worldpack. com.br/artigos /200Anos.pdf

29. Cardoso, J. G. R., Carvalho, P. S. L., Fonseca, P. S. M., Silva, M. M., \& Rocio, M. A. R. (2010). A indústria do alumínio: estrutura e tendências. BNDES Setorial, 33, 43-88. Recuperado em 28 de agosto de 2014, de http://www.bndes.gov.br/SiteBNDES/ export/sites/default/bndes_pt/Gale rias/Arquivos/conhecimento/ bnset/set3302.pdf

30. Associação Técnica Brasileira das Indústrias Automáticas de Vidro - ABIVIDRO. (2012). Vidro no Brasil e sua industria. São Paulo. Recuperado em 28 de agosto de 2014, de http:// www.abividro.org.br/abivi dro/vidro-no-brasil-e-sua-industria

31. Associação Brasileira de Celulose e Papel - BRACELPA. (2014). Conjuntura BRACELPA. Recuperado em 3 de julho de 2014, de http://bracelpa.org.br/bra2/sites/default/files/ conjuntura/CB-064.pdf

32. Associação Brasileira de Normas Técnicas - ABNT. (2004). NBR 10004: resíduos sólidos: classificação. Rio de Janeiro. Recuperado em 7 de julho de 2014, de http://www.aslaa.com. br/legislacoes/NBR\%20n\%2010004-2004.pdf

33. Associação Brasileira de Empresas de Limpeza Pública e Resíduos Especiais - ABRELPE. (2012). Panorama dos resíduos sólidos no Brasil. São Paulo. Recuperado em 28 de agosto de 2014, de http://www.abrelpe.org.br/Panorama/ panorama2012.pdf

34. Compromisso Empresarial para Reciclagem-CEMPRE. (2013). CEMPRE review. São Paulo. Recuperado em 28 de agosto de 2014, de http://cempre.org.br/download.php?arq=b18xO TVhNmJvOHExNHNka zZsMW42bzFzdTFxMGxhLnBkZg==

35. Oliveira, L. G. B. (2007). The conscientious consumption of sustainable packings. In Congresso Internacional de Pesquisa em Design (pp. 7). Belo Horizonte.

36. Amadeu, F. B.; Saran, G. M; Lourenzo, H. C.; Castro, M. C \& Fonseca, S. A. (2005). Politicas públicas e resíduos na Região Araraquara - São Carlos. In Anais do Encontro Nacional de Gestão Empresarial e Meio Ambiente. Rio de Janeiro. CDROM.

37. Lei $n^{\circ} 12.305$, de 2 de agosto de 2010. Política Nacional de Resíduos Sólidos Institui a Política Nacional de Resíduos Sólidos; altera a Lei no 9.605, de 12 de fevereiro de 1998; e dá outras providências. Diário Oficial da União, Brasília.

38. Pardo, G., \& Zufía, J. (2012). Life cycle assessment of foodpreservation technologies. Journal of Cleaner Production, 28, 198-207. http://dx.doi.org/10.1016/j.jclepro.2011.10.016.

39. Suput, D. Z., Lazić, V. L., Lević, L. B., Krkić, N. M., Tomović, V. M., \& Pezo, L. (2013). Characteristics of meat packaging materials and their environmental suitability assessment. Hemijska Industrija, 67(4), 615-620. http://dx.doi.org/10.2298/ HEMIND120907104S.

40. Williams, H., \& Wikström, F.-J. (2011). Environmental impact of packaging and food losses in a life cycle perspective: a comparative analysis of five food items. Journal of Cleaner Production, 19(1), 43-48. http://dx.doi.org/10.1016/j. jclepro.2010.08.008.

41. Wikström, F., Williams, H., Verghese, K., \& Clune, S. (2014). The influence of packaging attributes on consumer behaviour in food-packaging life cycle assessment studies - a neglected topic. Journal of Cleaner Production, 73, 100-108. http:// dx.doi.org/10.1016/j.jclepro.2013.10.042.

42. Comissão Mundial sobre Meio Ambiente e Desenvolvimento - CMMAD. (1991). Nosso Futuro Comum. Rio de Janeiro: Fundação Getúlio Vargas. 
43. Schmidheiny, S. (1996). Cambiando el rumbo: uma perspectiva global del empresariado para eldesarrollo y el médio ambiente. México: Fondo de Cultura Econômica.

44. Guelbert, T. F., Guelbert, M., Correa, M., Leszczynski, S. A. C., \& Guerra, J. C. C. (2007). A embalagem PET e a reciclagem: uma visão econômica sustentável para o planeta. In Anais do XXVII Encontro Nacional de Engenharia de Produção (pp. 1-11). Foz do Iguaçu: ANPAD.

45. Instituto Brasileiro de Geografia e Estatística - IBGE. (2010). Indicadores de desenvolvimento sustentável. Brasília.

46. Instituto Sócio-Ambeintal dos Plásticos - PLASTIVIDA. (2010). Monitoramento dos Índices de Reciclagem Mecânica de Plástico no Brasil (IRmP). São Paulo.

47. Instituto de Pesquisa Econômica Aplicada - IPEA. (2012). Diagnóstico dos resíduos sólidos urbanos. Brasília. Relatório de pesquisa.

48. Associação Brasileira da Industria de PET - ABIPET. (2010). Reciclagem: beneficio da reciclagem do PET. São Paulo. Recuperado em 28 de agosto de 2014, de http://www.abipet. org.br/index.html?method $=$ mostrarInstitucional\&id $=49$

49. Rolim, M. A. (2000). A reciclagem de resíduos sólidos pósconsumo em oito empresas do Rio Grande do Sul (Dissertação de mestrado). Universidade Federal do Rio Grande do Sul, Porto Alegre.

50. Al-Salem, S. M., Lettieri, P., \& Baeyens, J. (2010). The valorization of plastic solid waste (PSW) by primary to quaternary routes: from re-use to energy and chemicals. Progress in Energy and Combustion Science, 36(1), 103-129. http://dx.doi.org/10.1016/j.pecs.2009.09.001.

51. Coltro, L., \& Duarte, L. C. (2013). Reciclagem de embalagens plásticas flexíveis: contribuição da identificação correta. Polimeros: Ciência e Tecnologia, 23(1), 128-134. http://dx.doi. org/10.1590/S0104-14282013005000008.

52. Silva, J. C., Oliveira, M. A., Pires, P. H., Silva, T. P., \& Rodrigues, M.(2011). Reciclagem energética: uma solução inovadora para o plástico não reciclável. e-Xacta, 4(2), 87-96. Recuperado em 28 de agosto de 2014, de www.unibh.br/revistas/exacta/

53. Associação Brasileira do Alumínio-ABAL. (2012). Relatório de Sustentabilidade 2012. São Paulo.

54. Pinto, D. M. J., Brandão, E. S. G., \& Nogueira, R. G. (2012). Revista Científica Linkania Master, 4(2), 1-16. Recuperado em 28 de agosto de 2014, de http://linkania.org/master/article/ view/88/65

55. Associação Brasileira de Celulose e Papel - BRACELPA. (2009). Conjuntura BRACELPA. Recuperado em 28 de agosto de 2014, de http://bracelpa.org.br/bra2/sites/default/files/co

56. World Business Council for Sustainable Development WBCSD. Recuperado em 7 de julho de 2014, de http://www. wbcsd.org/Pages/EDocument/EDocumentDetails.aspx?ID= 13589\&NoSearhContextKey $=t$ rue

57. Kayo, C., Hashimoto, S., \& Moriguchi, Y. (2012). Paper and paperboard demand and associated carbon dioxide emissions in Asia through 2050. Journal of Industrial Ecology, 15(4), 529-540. http://dx.doi.org/10.1111/j.1530-9290.2011.00419.x.

58. Ghose, A., \& Carrasco, G. C. (2013). Environmental aspects of Norwegian production of pulp fibres and printing paper. Journal of Cleaner Production, 57, 293-301. http://dx.doi. org/10.1016/j.jclepro.2013.06.019.

59. Gaudreault, C., Samson, R., \& Stuart, P. R. (2010). Energy decision making in a pulp and paper mill: selection of LCA system boundary. Journal of Life Cycle Assessment, 15(2), 198-211. http://dx.doi.org/10.1007/s11367-009-0125-1.

60. Bajpai, P. (2014). Recycling and deinking of recovered paper. London: Elsevier.
61. Bedante, G. N. (2004). A influência da consciência ambiental e das atitudes em relação ao consumo sustentável na intenção de compra de produtos ecologicamente embalados (Dissertação de mestrado). Universidade Federal do Rio Grande do Sul, Porto Alegre.

62. Baraúna, D. (2009). Sistema de gestão ambiental (SGA): uma aplicação na produção de papel reciclado artesanal com adição de diferentes frações mássicas de fibras de bananeira (Dissertação de mestrado). Universidade da Região de Joinville, Joinville.

63. Suciu, N. A., Tiberto, F., Vasileiadis, S., Lamastra, L., \& Trevisan, M. (2013). Recycled paper-paperboard for food contact materials: contaminants suspected and migration into foods and food simulant. Food Chemistry, 141(4), 4146-4151. http:// dx.doi.org/10.1016/j.foodchem.2013.07.014. PMid:23993598.

64. Undri, A., Rosi, L., Frediani, M., \& Frediani, P. (2014). Fuel from microwave assisted pyrolysis of waste multilayer packaging beverage. Fuel, 133(1), 7-16. http://dx.doi.org/10.1016/j. fuel.2014.04.092.

65. Borges, D. G. (2007). Aproveitamento de embalagens cartonadas em compósito de polietileno de baixa densidade (Dissertação de mestrado). Universidade de São Paulo, São Paulo.

66. Fernandes, J. S., Danielewicz, R. J., \& Secco, J. (2014). Isolamento térmico de residências através da reutilização de embalagens Treta Pak. Revista Brasileira de Extensão Universitária, 5(1), 13-17.

67. Souza, F. F.(2011). Proposta metodológica para aplicação de logística reversa de embalagens cartonadas no âmbito municipal (Dissertação de mestrado). Universidade Federal do Paraná, Curitiba.

68. Agamuthu, P., \& Visvanathan, C. (2014). Extended producer responsibility schemes for used beverage carton recycling. Waste Management \& Research, 32(1), 1-3. http://dx.doi. org/10.1177/0734242X13517611. PMid:24396036.

69. Mediagroup. (2011). Relatório de sustentabilidade. São Paulo. Recuperado em 7 de julho de 2014, de http://www.mediagroup. com.br/host/tetrapak/2011/port/ra/06.htm\#

70. Compromisso Empresarial para Reciclagem - CEMPRE. (2014). Embalagem longa-vida. São Paulo. Recuperado em 7 de janeiro de 2014, de http://cempre.org.br/artigo-publicacao/ ficha-tecnica/id/9/em balagens-longa-vida

71. Lages, N. S., \& Vargas Neto, A.(2002). Mensurando a consciência ecológica do consumidor: um estudo realizado em Porto Alegre. In Anais do $26^{\circ}$ EnANPAD (pp. 15). Salvador: ANPAD.

72. Brasil. Ministério do Meio Ambiente. Agenda ambiental na administração pública. Brasília. Recuperado em 23 de novembro de 2015, de http://www.mma.gov.br/responsabilidadesocioambiental/a3p/item $/ 8852$

73. Brito, G. F., Agrawal, P., Araújo, E. M., \& Mélo, T. J. A. (2011). Biopolímeros, polímeros biodegradáveis e polímeros verdes. Revista Eletrônica de Materiais e Processos, 6(2), 127-139. Recuperado em 28 de agosto de 2014, de http://cct.ufcg.edu. br/revista/index.php/REMAP/article/vie wFile/222/204

74. Srinivasan, S., \& Lu, W. F. (2014). Development of a supporting tool for sustainable fmcg packaging designs. Procedia CIRP, 15, 395-400. http://dx.doi.org/10.1016/j.procir.2014.06.079.

75. Kumar, M., Mohanty, S., Nayak, S. K., \& Rahail Parvaiz, M. (2010). Effect of glycidyl methacrylate (GMA) on the thermal, mechanical and morphological property of biodegradable PLA/PBAT blend and its nanocomposites. Bioresource Technology, 101(21), 8406-8415. http://dx.doi.org/10.1016/j. biortech.2010.05.075. PMid:20573502.

76. Yam, K. L. (1986). The Wiley encyclopedia of packaging technology. New York: Wiley. 
Landim, A. P. M., Bernardo, C. O., Martins, I. B. A., Francisco, M. R., Santos, M. B., \& Melo, N. R.

77. Franchetti, S. M. M., \& Marconato, J. C. (2006). Polímeros biodegradáveis: uma solução parcial para diminuir a quantidade dos resíduos plásticos. Quimica Nova, 29(4), 811-816. http:// dx.doi.org/10.1590/S0100-40422006000400031.

78. Mali, S., Grossmann, M. V. E., \& Yamashita, F. (2010). Filmes de amido: produção, propriedades e potencial de utilização. Semina: Ciências Agrárias, 31(1), 137-156. http://dx.doi. org/10.5433/1679-0359.2010v31n1p137.

79. Bucci, D. Z., Tavares, L. B. B., \& Sell, I. (2005). Packinging for the storage of food products. Polymer Testing, 24(5), 564571. http://dx.doi.org/10.1016/j.polymertesting.2005.02.008.

80. Lima, S. L. T. (2004). Reciclagem e biodegradação de plásticos. Revista Cientifica do IMAPES, 2(2), 28-34.

81. Bardi, M. A. G., \& Rosa, D. S. (2007). Avaliação da biodegradação em solo simulado de poli ( $\varepsilon$-caprolactona), acetato de celulose e suas blendas. Revista Brasileira de Aplicações de Vácuo, 26(1), 43-47. http://dx.doi.org/10.17563/rbav.v26i1.15.
82. Mohanty, A. K., Misra, M., Drzal, L. T., Selke, S. E., Harte, B. R., \& Hinrichsen, G. (2005). Natural fibers, biopolymers, and biocomposites. Boca Raton: Taylor \& Francis. http://dx.doi. org/10.1201/9780203508206.

83. Belgacem, M. N., \& Gandini, A. (2008). Monomers, polymers and composites from renewable resources. Amsterdam: Elsevier.

84. Falcone, D. M. B; Agnelli, J. A. M., \& Faria, L I. L. (2007). Panorama setorial e perspectivas na área de polímeros. Polímeros: Ciência e Tecnologia, 17(1), 5-9. http://dx.doi. org/10.1590/S0104-14282007000100005.

Enviado: Ago. 28, 2014 Revisado: Jun. 09, 2015 Aceito: Jul. 22, 2015 